\title{
Technical Potential Assessment for the Renewable Energy Zone (REZ) Process: A GIS-based Approach
}

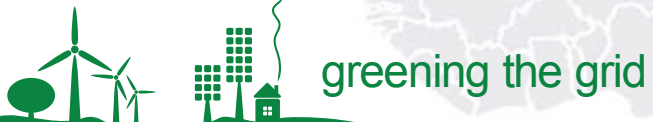

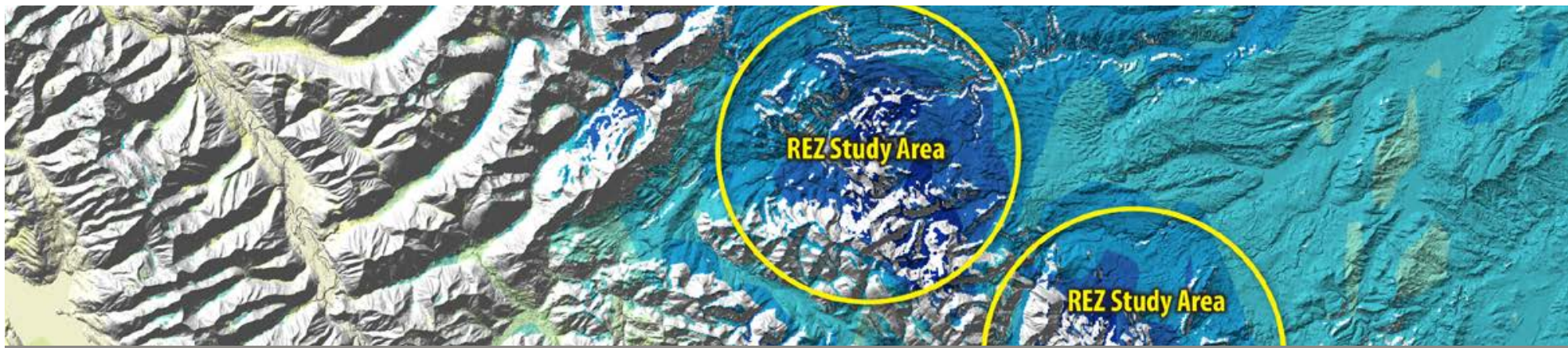

Geographic Information Systems (GIS)-based energy resource and technical potential assessments identify areas capable of supporting high levels of renewable energy (RE) development as part of a REZ process. This document expands on the discussion of Step 2 of the REZ Process to aid practitioners in conducting GIS-based RE resource and technical potential assessments.

Resource Potential The resource potential represents the

Total theoretical potential of a renewable energy resource

- Solar - Hydropower

- Wind - Geothermal

- Biomass

- Hydrokinetic

Technical Potential

Estimated potential after applying constraints

- System type - Terrain slope

- System size - Waterbodies

- Land use - Transmission

For more information see [2, 3]

Economic Potential

Estimated potential after financial considerations

- Projected technology costs

- Available vs. required revenue

For more information see [4]

\section{Market Potential}

Estimated potential after market considerations

- Competition with other energy sources

- Policy implementation and impacts

- Regulatory limits

- Investor response theoretical availability of an energy resource (such as wind speed or solar irradiance) in a defined region. Successive analyses of resource, technical, economic, and market potential yield estimates of power generation and cost under realistic conditions.

Technical potential estimates the capacity of an RE technology (solar PV, wind, etc.) available for development after accounting for topographic limitations, land-use constraints, and system performance. This is assessed with GIS by filtering out areas that are not technically feasible for development. Once feasible land areas are identified, technology-specific system modeling calculates maximum electric power generation based on resource, available land, and various system assumptions.

The technical potential assessment enables the initial identification of study areas that are technically capable of supporting high-quality RE resource development. Following the technical potential analysis, economic analyses can further filter the study areas based on economic considerations such as technology costs, applicable incentives, electricity prices, among others. In subsequent steps of the REZ process, developers are invited to demonstrate interest in those areas that have the highest probability of commercial development.
The REZ Transmission

\section{Planning Process}

The renewable energy zone (REZ) transmission planning process is an approach to connect areas with concentrated RE resources to the power grid. The process helps to plan, approve, and build transmission infrastructure to access areas with highquality resources, suitable topography and land-use designations, and demonstrated developer interest-supporting reliable and economic integration of RE.

Step 1. Process Design \& Vision Statement

Step 2. Renewable Energy Resource Assessment

Step 3. Candidate Zones Selection

Step 4. Transmission Options Development

Step 5. Final Transmission Plan Designation

Step 6. Transmission System Upgrade

The Renewable Energy Zone (REZ) Transmission Planning Process: A Guidebook for Practitioners details each step of the REZ process from setting a vision through to final transmission system upgrades [1]. 


\section{How a GIS-Based Technical Potential Assessment is Completed in the REZ Process}

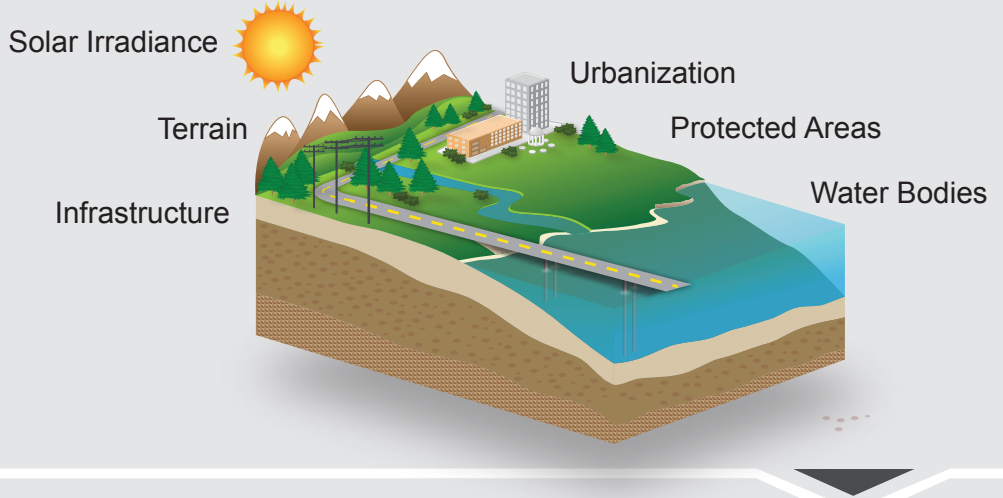

\section{(1) Identify Constraints and Collect Data \\ The technical potential assessment begins with the} collection or development of data on RE resources (e.g., wind speed, solar irradiance, etc.) and geographic features that may be barriers to development such as dense urban areas, rugged terrain, large water bodies, and protected areas. These and possibly more constraints need to be considered during the identification of study areas in the REZ process. The data collected in this step is then used in the analyses conducted in step 2.

\section{(2) Conduct Technical Potential Analyses}

The RE resource data and geographic features from step 1 are represented as data layers that can be combined and analyzed. RE resource data are analyzed to estimate power generation by modeling generation system (wind, solar PV) size, operating hours, and other considerations. The result is then used in an exclusion layer analysis.

Supercomputers and geodatabases store, process, and analyze terrabytes of timeseries data spanning the globe. Results can be loaded into online tools like RE Data Explorer (www.re-explorer.org) for further visualization and analysis.

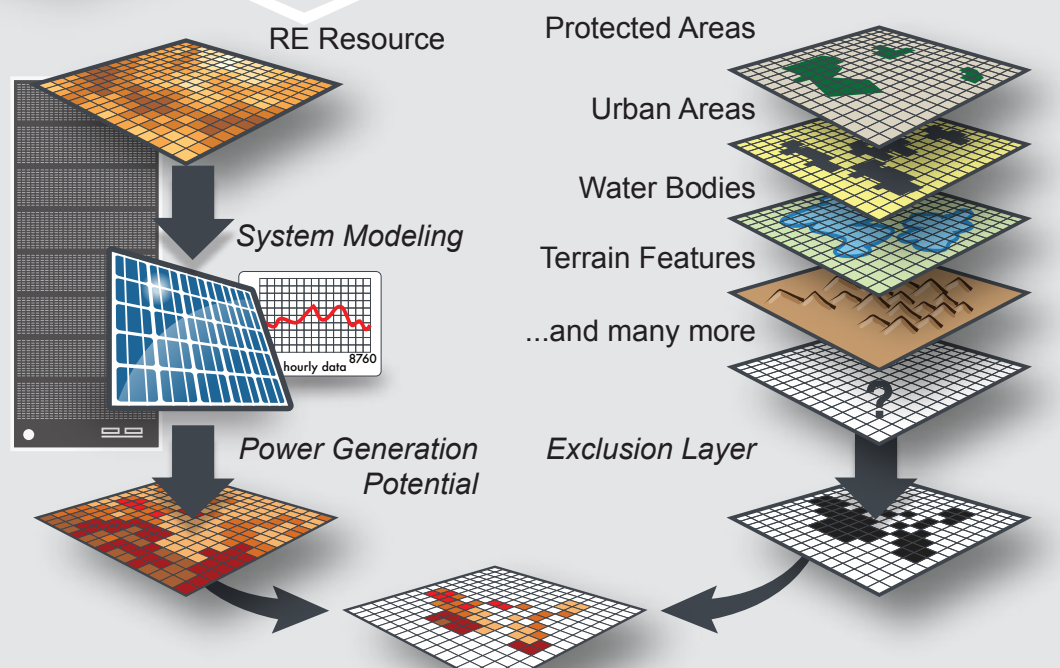

An exclusion layer analysis identifies the technically feasible areas by systematically filtering out areas that have development constraints and highlighting priority areas for development. This analysis may consider multiple scenarios of potential development exclusions.

Step 2 identifies areas with attractive technical potential and development opportunities.

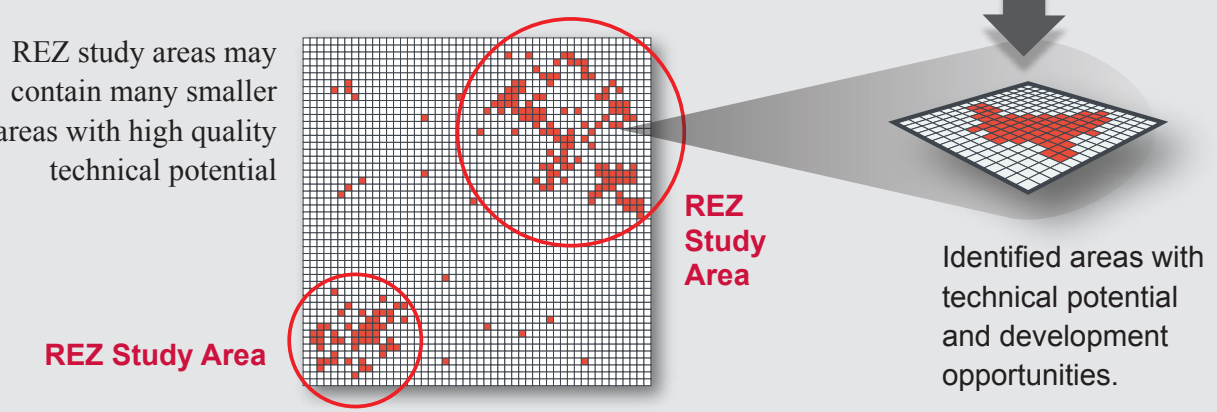

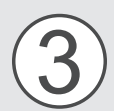

Perform Further Analysis and Mapping

The technical potential analysis identifies study areas that could support high levels of RE development. In the next steps, economic analyses can help to further filter the study areas based on economic considerations such as the cost of generation.

Learn more about technical and economic potential analyses and additional REZ process steps with the REZ Toolkit online at: greeningthegrid.org

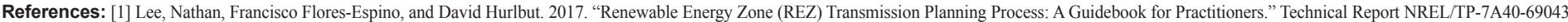
Golden, CO: National Renewable Energy Laboratory (NREL). www.nrel.gov/docs/fy 17osti/69043.pdf.

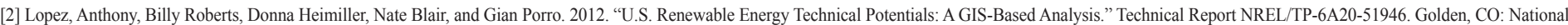
Renewable Energy Laboratory (NREL). www.nrel.gov/docs/fy12osti/51946.pdf.

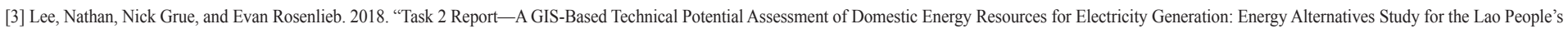

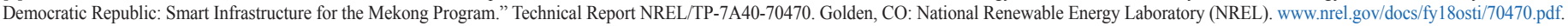

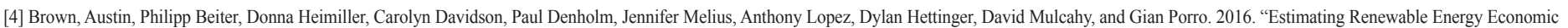
Potential in the United States: Methodology and Initial Results.” Technical Report NREL/TP-6A20-64503. Golden, CO: National Renewable Energy Laboratory (NREL). www.nrel.gov/docs/fy15osti/64503.pdf.

Written by Nathan Lee and Billy Roberts, National Renewable Energy Laboratory

The REZ Toolkit is a collection of resources to help power system planners, developers, key decision makers, and stakeholders understand and use the REZ transmission planning process to integrate transmission expansion planning and renewable energy generation planning. For more information:
The REZ Toolkit is part of the Greening the Grid technical platform, which addresses the technical challenges around grid modernization and state-of-the-art practices in bringing advanced energy technologies into the power sector. Greening the Grid is supported by the U.S. Agency for International Development.

NREL is a national laboratory of the U.S. Department of Energy, Office of Energy Efficiency \& Renewable Energy, operated by the Alliance for Sustainable Energy, LLC.

NREL/TP-7A40-71004 • April 2018 